minal vasodilators for postoperative vasospasm (LITA and native coronary spasm). Our patient was successfully treated with papaverine injected intraluminally through angiographic catheterization. This has not been reported before. In our search of the English literature, only one case report of internal thoracic artery spasm refractory to angiographic intraluminal injection with nitroglycerin was found. ${ }^{3}$ In our case, intraluminal nitroglycerin was ineffective in relieving the LITA spasm. Papaverine inhibits oxidative phosphorylation but may cause vasodilatation by inhibiting phosphodiesterase, which prevents breakdown of cyclic nucleotides. Angiographic intraluminal papaverine prevents the complications of surgical delay, reoperation, graft manipulation, external graft injection of vasodilators, repeated use of cardiopulmonary bypass, and additional grafting.

\section{References}

1. Sarabu MR, McClung JA, Fass A, Reed GE. Early postoperative spasm in left internal mammary artery bypass grafts. Ann Thorac Surg. 1987; 44:199-200

2. Paterson HS, Jones MW, Baird DK, Hughes CF. Lethal postoperative coronary artery spasm. Ann Thorac Surg. 1998;65:1571-3.

3. Kitamura H, Nakayama K, Kitano T. A case of refractory spasm of multiple coronary arteries and left internal thoracic artery graft following off-pump CABG. Kyobu Geka. 2001;54:1103-6.

4. Yoshida S, Sakuma K, Yokoyama H, Oda K. [Coronary vasospasm during off-pump coronary artery bypass grafting: report of two cases.] Japanese. Kyobu Geka. 2003;56:585-8.

5. He GW. Contractility of the human internal mammary artery at the distal section increases toward the end. Emphasis on not using the end of the internal mammary artery for grafting. J Thorac Cardiovasc Surg. 1993;106:406-11.

\title{
Stenosis of the grafted portion of the coronary artery after aortic root replacement with a Freestyle prosthesis
}

Masanori Murakami, MD, ${ }^{\text {a }}$ Haruhiko Okada, MD, ${ }^{a}$ Masahiko Nishida, MD, ${ }^{a}$ and Kimikazu Hamano, MD, ${ }^{\text {b }}$ Yamaguchi, Japan

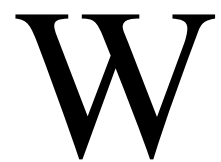
e report a case of stenosis at the grafted portion of the coronary artery after aortic root replacement with a Freestyle prosthesis (Freestyle Aortic Root Bioprosthesis; Medtronic, Inc, Minneapolis, Minn). The coronary artery was reconstructed with the full root technique. There was no displacement or flexion of the coronary artery graft as a result of the surgical procedure. Aspirin was used as a postoperative anticoagulant. A coronary angiogram obtained 18 months after the surgery showed $90 \%$ stenosis at the left coronary ostium (Figure 1) and 75\% stenosis at the right coronary ostium. No stenosis (0\%) was observed after percutaneous coronary intervention (PCI). After PCI, the patient received adequate doses of warfarin sodium and aspirin. The follow-up coronary angiogram (at 18 months) showed no graft stenosis. This is the first

\footnotetext{
From the Division of Cardiovascular Surgery, Shakaihoken Tokuyama Central Hospital, a and the First Department of Surgery, Yamaguchi University School of Medicine, ${ }^{\mathrm{b}}$ Yamaguchi, Japan.

Received for publication April 8, 2005; accepted for publication April 25, 2005.

Address for reprints: Masanori Murakami, MD, Division of Cardiovascular Surgery, Shakaihoken Tokuyama Central Hospital, Kohdachoh 1-1, Shunan, Yamaguchi 745-8522, Japan (E-mail: surg-1@ yamaguchi-u.ac.jp).

J Thorac Cardiovasc Surg 2005;130:940-1

$0022-5223 / \$ 30.00$

Copyright $\odot 2005$ by The American Association for Thoracic Surgery doi:10.1016/j.jtcvs.2005.04.024
}

English-language re-

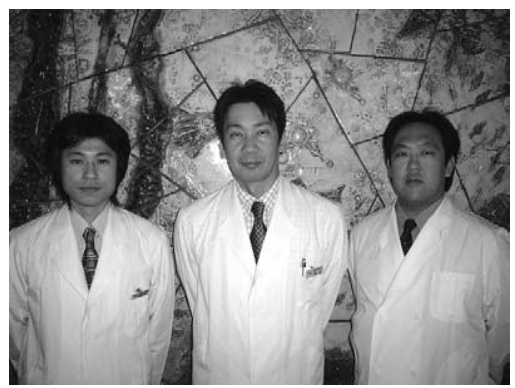
port of PCI performed for coronary graft stenosis after aortic root replacement with a Freestyle prosthesis.

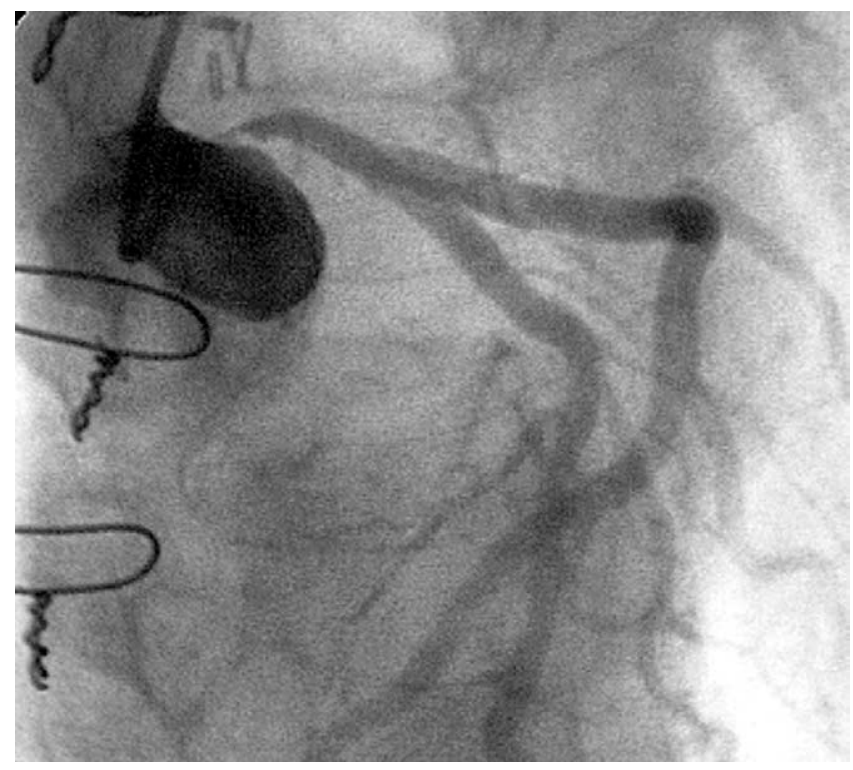

Figure 1. Angiogram of reconstructed left coronary artery showing $\mathbf{9 9 \%}$ stenosis of grafted portion. 


\section{Clinical Summary}

A 71-year-old woman with aortic stenosis, which had been diagnosed on echocardiography by a private physician, and with no known significant medical history was referred to our hospital for definitive diagnosis and management. Coronary angiography revealed a pressure gradient of $80 \mathrm{~mm} \mathrm{Hg}$ between the left ventricle and aorta and grade 2 aortic regurgitation. At the preoperative stage, coronary artery stenosis was not observed. The echocardiographic findings were as follows: grade 2 aortic regurgitation, left ventricle end-diastolic volume/end-systolic volume ratio of 48/30, ejection fraction of $68 \%$, left ventricle posterior wall thickness of $11 \mathrm{~mm}$, left ventricle-aorta pressure gradient of $105 \mathrm{~mm} \mathrm{Hg}$, and aortic valve area of $0.5 \mathrm{~cm}^{2}$. A tricuspid aortic valve with severe calcification was observed during the operation. The size of the excised valve suggested that a $21-\mathrm{mm}$ prosthetic valve would be a suitable replacement. A 21-mm Medtronic Freestyle porcine valve was chosen to replace the native valve and aortic root with the full root technique. Both coronary ostia were mobilized on $10-\mathrm{mm}$ buttons of the aortic wall. Next, the prosthetic valve was trimmed to create an opening for the mobilized coronary ostia by excising generous buttons of porcine aortic tissue from the left and right coronary sinuses present on the sinus of Valsalva. After confirmation of the proper positioning of the valve within the aorta, each coronary ostium was reimplanted by suturing its button of the aortic wall with a 5-0 Prolene (Ethicon, Inc, Somerville, NJ) suture by the parachute method. Intraoperative transesophageal echocardiography revealed no abnormality in the coronary ostia. Aspirin was used as a postoperative anticoagulant. The patient's clinical course after her discharge from the hospital was unevent- ful. The patient visited the cardiovascular internal medicine department of our hospital 18 months after the surgery with reports of exertional chest pain. Electrocardiography showed negative $\mathrm{T}$ waves in leads II, III, aVF, and $\mathrm{V}_{3}$ to $\mathrm{V}_{6}$. Coronary angiography showed $90 \%$ stenosis of the left coronary ostium (Figure 1) and $75 \%$ stenosis of the right coronary ostium. PCI was performed, after which there was no stenosis $(0 \%)$, and the chest pain disappeared. After PCI, the patient received adequate dosages of warfarin and aspirin for 18 months; no chest pain or stenosis was observed during that period.

\section{Discussion}

We used a Freestyle prosthesis for aortic stenosis involving a small aortic valve area. Some cases of occlusion of the coronary graft after the Bentall operation have been reported., ${ }^{1,2}$ Displacement and flexion of the coronary artery were not observed during the procedure. We therefore believe that the stenosis was not due to the surgical technique. The possibility that the stenosis was caused by cardioplegic cannulation after aortic root replacement with a Freestyle prosthesis should be considered.

\section{References}

1. Balbi M, Olivotti L, Scarano F, Bertero G, Passerone G, Brunelli C, et al. Percutaneous treatment of left main coronary stenosis as a late complication of Bentall operation for acute aortic dissection. Catheter Cardiovasc Interv. 2004;62:343-5.

2. Kamei F, Murasato Y, Tsurugi T, Ando H. A case report of percutaneous coronary intervention for an occluded coronary graft in a patient with Marfan syndrome who underwent a Bentall operation. Jpn J Interv Cardiol. 2004;19:528-33. 